\title{
Whale songs lengthen in response to sonar
}

\author{
Male humplbacks modify their sexual displays when exposed to man-made noise.
}

eff here is growing concern about the effects of man-made noise on marine life. In particular, marine mammals that use sound to communicate, navigate, and detect predators and prey may try to avoid loud sound sources up to tens of kilometres away ${ }^{1}$. Here, in a study conducted in cooperation with the US Navy², we show that the singing behaviour of male humpback whales was altered when they were exposed to LFA (low-frequency active) sonar. As the song of these whales is associated with reproduction ${ }^{3}$, widespread alteration of their singing behaviour might affect demographic parameters, or it could represent a strategy to compensate for interference from the sonar.

During the breeding season male humpback whales sing long, complex songs that are thought to be sexual displays ${ }^{3}$. Songs consist of a series of themes, progressing in

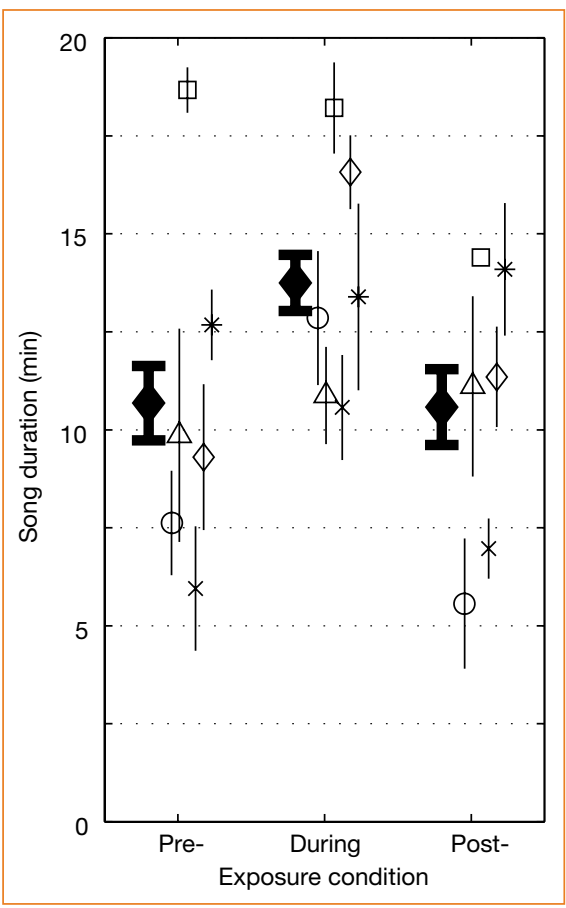

Figure 1 Duration of songs ( \pm s.e.m.) produced by humpbacks before, during and after exposure to LFA sonar transmissions (bold, filled diamonds, mean of all six singers; other symbols, individual singers). The maximum received level of the sonar at the whale ranged from 130 to $150 \mathrm{~dB}$ re $1 \mu \mathrm{Pa}$. Songs were grouped in the exposure condition if a sonar transmission occurred at any point during the song. The average number of songs per singer in the pre-exposure, exposure and post-exposure conditions was 3.2, 4.7 and 3.8, respectively. Differences were assessed using a mixed-model analysis of variance treating exposure condition as a fixed factor, whale identity as a random factor, and each song duration as an independent observation. The effect of exposure condition on song duration was statistically significant at $P=0.047\left(F_{2,10}=4.200\right.$, power $\left.=0.50, n=6\right)$. a predictable order, that may repeat for several hours ${ }^{4}$. We used a small observation vessel to find singing humpbacks and conduct focal sampling ${ }^{5}$, recording behaviour before, during and after playback. (Strictly speaking, we have evaluated the additional impact that LFA sounds have on a singing whale that is already being followed.)

We recorded the vocal behaviour of each focal singer continuously for several hours using a towed, calibrated hydrophone array $^{6}$. When the whale was at the surface, observers sampled visible behaviour. Photographs of fluke and dorsal fin features confirmed the whale's identity throughout each follow ${ }^{7}$. At least two songs were recorded before the observation vessel requested the US Navy R/V Cory Chouest to transmit ten (in one case four) 42-s LFA signals at 6-min intervals. The sonar was broadcast at less than full strength, and no focal singer was exposed to a signal louder than $150 \mathrm{~dB}$ (with respect to $1 \mu \mathrm{Pa}$ ).

Sixteen singers were followed during 18 playbacks. In nine follows, the whale sang continuously throughout the playback; in four the singer stopped when he joined other whales (typical of normal social interaction); and in five the singer stopped, presumably in response to the playback. We recorded at least one complete song in all conditions from six individuals, and pooled the songs of each of the two individuals that were subjects in two experiments. For these six whales, we measured the duration and theme structure of song spectrograms, comparing song duration in the three conditions using analysis of variance ${ }^{8}$.

On average, humpback whales' songs were $29 \%$ longer during LFA playbacks

\section{Nutrition}

\section{Antioxidant activity of fresh apples}

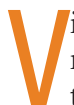
itamin $\mathrm{C}$ is used as a dietary supplement because of its antioxidant activity, although a high dose $(500 \mathrm{mg})$ may act as a pro-oxidant in the body ${ }^{1,2}$. Here we show that $100 \mathrm{~g}$ of fresh apples has an antioxidant activity equivalent to $1,500 \mathrm{mg}$ of vitamin $\mathrm{C}$, and that whole-apple extracts inhibit the growth of colon- and livercancer cells in vitro in a dose-dependent manner. Our results indicate that natural antioxidants from fresh fruit could be more effective than a dietary supplement.

Apples of the Red Delicious variety were
(Fig. 1) - a particularly strong result, given the low power of the test and small sample size 9 . Song duration returned to normal after exposure, suggesting that this response has a limited duration. There was little difference in the likelihood of an aberrant theme transition across exposure conditions $\left(\chi^{2}=3.273, P=0.195\right)$, indicating that long songs resulted from longer themes within a normal song structure. Across the six singers, maximum received level of the sonar at the whale did not correlate positively with either the increase in mean song duration from pre-exposure to exposure condition $(r=-0.90)$ or with the subsequent decrease from exposure to post-exposure condition $(r=-0.63)$.

We suggest that humpbacks sang longer songs during LFA sonar transmissions to compensate for acoustic interference. Our study shows that it is possible to measure the behavioural responses of individual whales in controlled experiments at sea.

Patrick J. O. Miller ${ }^{\star}$, Nicoletta Biassoni*, Amy Samuels ${ }^{\star} \dagger$, Peter L. Tyack

${ }^{*}$ Biology Department, Woods Hole Oceanographic Institution, Woods Hole, Massachusetts 02543, USA $\dagger$ Daniel F. and Ada L. Rice Conservation Biology and Research Center, Chicago Zoological Society, Brookfield, Illinois 60513, USA

\footnotetext{
1. Richardson, W. J., Greene, C. R. Jr, Malme, C. I. \& Thomson, D. H. Marine Mammals and Noise (Academic, San Diego, 1995). 2. Waters, M. A. US Federal Register 61, 37452-37453 (1996).

3. Tyack, P. L. Behav. Ecol. Sociobiol. 8, 105-116 (1981).

4. Payne, R. \& McVay, S. Science 173, 585-597 (1971).

5. Altmann, J. Behaviour 49, 227-267 (1974).

6. Miller, P. J. \& Tyack, P. L. Deep-Sea Res. II 45, 1389-1405 (1998).

7. Katona, S. et al. in The Behavior of Marine Mammals (eds Winn, H. E. \& Olla, B. L.) 33-44 (Plenum, New York, 1979).

8. Zar, J. H. Biostatistical Analysis (Prentice-Hall, Englewood Cliffs, NJ, 1984).

9. Lehmann, E. L. Ann. Math. Stat. 29, 1167-1176 (1958).
}

extracted using $80 \%$ acetone and their content of phenolics and flavonoids determined $^{3,4}$ : the extracts contained $290.2 \pm 4.2$ and $219.8 \pm 1.8 \mathrm{mg}$ phenolics, and $142.7 \pm 3.7$ and $97.6 \pm 3.9 \mathrm{mg}$ flavonoids per $100 \mathrm{~g}$ apples with and without skin, respectively. There are known to be more phenolics in the skins of apples than in the flesh, and quercetin glycosides are found only in the skins ${ }^{5}$.

We measured the total antioxidant activity of apples by using the total oxyradicalscavenging capacity (TOSC) assay ${ }^{6}$ and found that apples with skin had a higher TOSC value than apples without skin (Fig. 1a). The total antioxidant activity of $1 \mathrm{~g}$ apples with skin was $83.3 \pm 8.9$ TOSC ( $\mu \mathrm{mol}$ vitamin $\mathrm{C}$ equivalents) — that is, the 

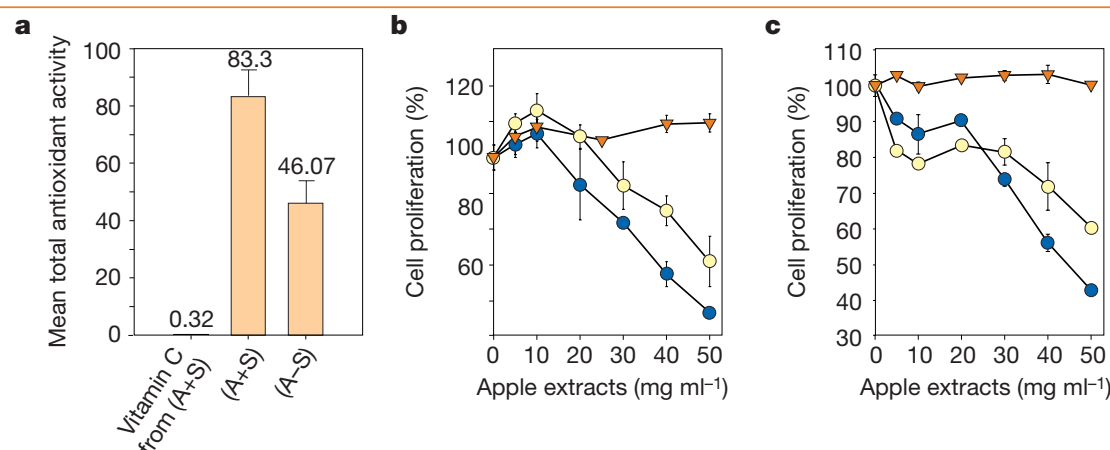

Figure 1 Antioxidant activity of apples and their effect on tumour-cell proliferation in vitro. a, Mean total antioxidant activity expressed by total oxyradical-scavenging capacity (TOSC; $\mu$ mol vitamin $C$ equivalents per $\mathrm{g}$ ) assay for $1 \mathrm{~g}$ apple with skin $(\mathrm{A}+\mathrm{S}$ ), and for apple without skin $(A-S)$. b, Inhibition of proliferation of Caco-2 colon-tumour cells by extracts of apple with and without skin. c, Inhibition of proliferation of HepG2 liver-tumour cells. Control samples were assayed as apple extracts, but they contained only vitamin $\mathrm{C}$ at the same concentration that exists in apples $\left(0.057 \mathrm{mg} \mathrm{g}^{-1}\right)$. Cell proliferation was determined by using the MTS assay ${ }^{10}$. Blue circles, apple with skin; yellow circles, apple without skin; orange triangles, control extracts.

antioxidant value of $100 \mathrm{~g}$ apples is equivalent to $1,500 \mathrm{mg}$ of vitamin C. Given that the average vitamin $\mathrm{C}$ content in fresh apples with skin is $5.7 \mathrm{mg}$ per $100 \mathrm{~g}$ (ref. 7) and that the total antioxidant activity of $0.057 \mathrm{mg}$ vitamin $\mathrm{C}$ (in $1 \mathrm{~g}$ of whole apples) is only 0.32 TOSC (Fig. 1a), then almost all of the antioxidant activity in apples must be due to phytochemicals.

We treated a colon-cancer cell line, Caco2 , with extracts equivalent to $0,5,10,20,30$, 40 and $50 \mathrm{mg} \mathrm{ml}^{-1}$ apples for 96 hours (the treatment time for maximal response). Cell proliferation was inhibited in a dose-dependent manner after exposure to apple-extract concentrations above $20 \mathrm{mg} \mathrm{ml}^{-1}$ (Fig. 1b): at $50 \mathrm{mg} \mathrm{ml}^{-1}$, inhibition was $43 \pm 1 \%$ and $29 \pm 4.1 \%$ for apples with skin and for apples without skin, respectively.

We also tested the effect of apple extracts on the proliferation of another cancer-cell line, HepG2 human liver-tumour cells. We found that apple extracts at $50 \mathrm{mg} \mathrm{ml}^{-1}$ inhibited the proliferation of these cells as well, by $57 \pm 0.21 \%$ and $40 \pm 0.64 \%$ for apples with and without skin, respectively (Fig. 1c). The extracts of apple with skin could thus significantly ( $t$-test, $P<0.031$ ) reduce tumour-cell proliferation compared with extracts of apples without skin. No cytotoxicity of the apple extracts was seen at any of the concentrations tested (data not shown).

We suggest that this strong inhibition of tumour-cell proliferation in vitro could be due to apples' combination of phytochemicals (phenolic acids and flavonoids), as these are natural antioxidants. It has been proposed that the consumption of whole fruits may provide the antioxidant balance needed to quench reactive oxygen species ${ }^{8}$ which have been implicated in tumorigenesis ${ }^{9}$. Phytochemicals in apples other than ascorbic acid seem significantly to enhance their antioxidant properties and their capacity to inhibit the proliferation of tumour cells in vitro.

\section{Marian V. Eberhardt, Chang Yong Lee,} Rui Hai Liu

Department of Food Science, 108 Stocking Hall, Cornell University, Ithaca, New York 14853-7201, USA

e-mail:RL23@cornell.edu

1. Podmore, I. D. et al. Nature 392, 559 (1998).

2. Herbert, V. et al. J. Nutr. 126, 1213S-1220S (1996) 144-158 (1965).

4. Zhisen, J., Mengcheng, T. \& Jianming, W. Food Chem. 64, 555-559 (1999)

5. Burda, S., Oleszek, W. \& Lee, C. Y. J. Agric. Food Chem. 38, 945-948 (1990).

6. Winston, G. W., Regoli, F., Dugas, A. J., Fong, J. H. \& Blanchard, K. A. Free Rad. Biol. Med. 24, 480-493 (1998).

7. USDA Nutrient Database for Standard Reference (1998).

8. Wang, H., Cao, G. \& Prior, R. L. J. Agric. Food Chem. 44, 701-705 (1998).

9. Lunec, J. J. Int. Fed. Clin. Chem. 4, 58-63 (1992). Commun. 3, 207-212 (1991).

\section{Botany}

nderstanding how the growth of trees at high latitudes in boreal forest is controlled is important for projections of global carbon sequestration and timber production in relation to climate change. Is stem growth of boreal forest trees constrained by the length of the growing season when stem cambial cells divide ${ }^{1}$, or by the length of the period when resources can be captured ${ }^{2}$ ? In both cases, the timing of the thaw in the spring is critical: neither cambial cell division nor uptake of nutrients and carbon dioxide can occur while the soil is frozen. Here we argue, on the basis of long-term observations made in northern Saskatchewan and Sweden, that the time between the spring thaw and the autumn freeze determines the amount of annual tree growth, mainly through temperature effects on carbon-dioxide uptake in spring
3. Singleton, V. L. \& Rossi, J. A. Jr Am. J. Enol. Viticult. 16,

10. Cory, A. H., Owen, T. C., Barltrop, J. A. \& Cory, J. G. Cancer

\section{Constraints to growth of boreal forests}

and on nutrient availability and uptake during summer, rather than on cambial cell division.

From tree-ring analysis across several sites in the Siberian subarctic, Vaganov et al. ${ }^{1}$ provide evidence that annual variability in mean ring width is determined by the date of the thaw through its influence on the date of cambial initiation, as well as by temperature during the subsequent early growing season. Variability in annual net ecosystem production (NEP) is also largely determined by the timing of the thaw ${ }^{3}$, which enables the NEP to switch immediately and rapidly from a daily loss to a daily gain of $\mathrm{CO}_{2}$.

Our own observations on black spruce trees at the Boreas Southern Study Area ${ }^{4}$ show that when air temperature exceeds $-1{ }^{\circ} \mathrm{C}$ and the overlying snow starts to melt, meltwater percolates down into the soil, the temperature of the upper soil horizons rises towards $0{ }^{\circ} \mathrm{C}$, and the switch from a small net daily loss of carbon to a large net gain occurs over just a few days. In boreal conifers, the availability of soil water is a prerequisite for the recovery of photosynthetic capacity in spring and early summer ${ }^{2}$.

The effect of frozen soils on annual $\mathrm{CO}_{2}$ uptake by Norway spruce at $64^{\circ} \mathrm{N}$ is particularly dramatic because, before the thaw, daily solar radiation is already substantial and effectively being wasted from the perspective of $\mathrm{CO}_{2}$ capture ${ }^{5}$. Thus, $\mathrm{CO}_{2}$ uptake is synchronized and strongly stimulated by the thaw, and afterwards, once a critical temperature sum is reached, cambial activity and NEP increase together as the temperature rises.

Such observations related to the poor growth of trees in boreal forests have led to the presumption that their growth is constrained by temperature. By contrast with temperate and tropical forests ${ }^{6}$, boreal forest trees are small in relation to their age and coniferous boreal forests have a very low net primary production of about 2.5 tonnes of carbon $\mathrm{ha}^{-1} \mathrm{yr}^{-1}$ (refs 7,8). To investigate the extent to which low temperature is the primary controlling variable, a long-term nutrient-optimization and irrigation experiment on Norway spruce was set up at Flakaliden $\left(64^{\circ} \mathrm{N}\right)$ in Sweden ${ }^{9}$. Since 1987, we have applied complete fertilizer daily through every growing season either in irrigation water or as a single solid dose at the start of the growing season. We found that growth on the fertilized plots (with or without irrigation) increased by a factor of four ${ }^{10}$ (Fig. 1a), so air temperature cannot be the major direct constraint on tree growth.

However, temperature may be influencing tree growth indirectly through the length of the growing season and by its effects on decomposition of soil organic 